\title{
Assessment of diet and recognition of nutritional deficiencies in paleopathological studies: A review
}

\author{
A. MEYER* \\ Department of Anatomy, School of Medicine, Faculty of Health Sciences, University of Pretoria, \\ Arcadia, Gauteng, South Africa \\ *Correspondence to: A. Meyer, Department of Anatomy, Faculty of Health Sciences, University of \\ Pretoria, Private Bag x323, Arcadia 0007, Gauteng, South Africa. E-Mail: anja.meyer@up.ac.za
}

\begin{abstract}
An essential part of paleopathology is the study of diet and nutrition as well as inferring aspects of diet and nutrition from the skeletal pathology. Interpretation of nutritional and metabolic disease-related pathologies often provides additional insight into the daily social and cultural practices of people. However, precise diagnoses of specific vitamin-related deficiencies in archaeological skeletal remains are still quite problematic and specific diagnoses are rarely possible. This partly stems from the fact that many nutritional or metabolic diseases do not necessarily result in an osteological response and when they do, the comorbidity and analogous osteological responses to vitamin deficiencies may hamper the definite diagnosis of nutrition-related disease. Clin. Anat. 29:862-869, 2016. (C) 2016 Wiley Periodicals, Inc.
\end{abstract}

\section{INTRODUCTION}

The study of paleopathology focuses on the identification and understanding of disease in ancient remains; be it from the few rare examples of mummified individuals or the more frequently encountered skeletonized remains of ancient populations. Central to the study of paleopathology is the assessment of diet and the recognition of nutritional deficiencies and its effects on the general health of an individual or a population. The study of diet in archaeological populations is traditionally concerned with the reconstruction of dietary patterns through studying associated faunal and floral remains, coprolites, or more directly by isotopic analysis of human collagen (Huss-Ashmore et al., 1982; Larsen, 2002). However, skeletal pathologies, especially those related to metabolic diseases, can aid in our understanding of the interaction between diet and health and how external factors such as environmental conditions and socio-cultural settings may influence this. In cases where nutritional or metabolic stress occurs the normal balance between osteoblastic and osteoclastic activity becomes disrupted, resulting in abnormal bone growth and/or remodeling (Brickley and Ives, 2008). The manifestation of osteological responses may therefore be used as a proxy for diet as underlying nutritional deficiencies may potentially produce distinctive remodeling. Definitive diagnosis of such skeletal pathologies can, however, be extremely problematic. This is largely due to the fact that bone is severely limited in its response to metabolic or nutrition-related insults. Added to that remains the fact that vitamin and/or mineral deficiencies often co-occur which makes it almost impossible to isolate the specific vitamin or mineral deficiency responsible for the skeletal 
pathology. The identification of a single causative agent may therefore not always be possible as vitamin and mineral deficiencies affecting the same physiological processes may also produce similar osteological responses (Huss-Ashmore et al., 1982).

For this reason, paleopathologists often focus on what is termed "general indicators of stress". These types of pathologies refer to the non-specific and sometimes quite subtle indications of the body's adaptive response to stressors like malnutrition and metabolic stress. Some of the first studies, which looked at identifying indicators of population stress, were done by Adams and Berridge (1969) on the effects of a low protein-calorie diet on the skeleton. Results from their research indicated that a deprivation in calories (marasmus) resulted in delayed development and a small stature whereas a lack of protein (kwashiorkor) in the diet resulted in cortical and trabecular bone thinning, especially in the metacarpals (Adams and Berridge, 1969).

Similarly, Angel $(1978,1982)$ examined the metric parameters of bone as a possible indicator for nutritional stress during childhood (Kozłowski and Witas, 2012). Angel's findings indicated a direct relationship between the pelvic brim index (1978) and skull base height (1982), and nutritional and health conditions. Nevertheless, these only serve as indirect indicators of childhood growth stress and do not provide conclusive insight into the specific dietary practices or metabolic diseases encountered by past populations.

In most paleopathological studies, specific osteological responses to stress and malnutrition are more often used to make inferences about populations' stress in general. Some of the more well-known indicators of stress are Harris lines and dental enamel hypoplasia. Harris lines are regarded as one of the most common indicators of skeletal "stress" and are frequently interpreted as a non-specific sign of stress in children (Harris, 1933; Larsen, 1997; Aufderheide and Rodríguez-Martin, 1998; Ortner, 2003). Yet often ascribed to malnutrition (Adams and Berridge, 1969; Aufderheide and Rodríguez-Martin, 1998; Ortner, 2003; Ameen et al., 2005), the etiology of Harris lines remains unclear and may include factors like illness and even psychogenic stress (Larsen, 1997; Papageorgopoulou et al., 2011; Weston, 2012). It has also recently been argued by Alfonso-Durruty (2011) and Papageorgopoulou et al. (2011) that Harris lines may be a factor of normal growth and growth spurts rather than an indicator of non-specific stress. Similarly enamel hypoplasia (Fig. 1) is frequently described as an indicator of nutritional and/or pathogenic stress (Aufderheide and Rodríguez-Martin, 1998; Ortner, 2003). Goodman and Rose (1991) describe enamel hypoplasia as a deficiency in enamel thickness, visible as transverse grooves or pits on the outer enamel surface. These defects occur as a result of disrupted ameloblast function and reduced secretion of enamel matrix during amelogenesis (Goodman and Rose, 1991; Lukacs, 2012). As enamel does not remodel, this condition acts as a permanent visual indicator for stress and is often reported on in the paleopathological literature (Roberts and Manchester, 2010; Aufderheide and Rodríguez-Martin, 1998; Ortner, 2003; Ogden, 2008; Lukacs, 2012). The etiology of enamel hypoplasia is also multiple and includes hereditary anomalies, localized trauma, and systematic metabolic stress brought on by nutritional deficiencies such as vitamin D and calcium deficiency, as well as continued episodes of childhood illness (Purvis et al., 1973; Ogden, 2008; Lukacs, 2012). Even though both these conditions can potentially be ascribed to nutritional deficiencies, the exact etiology cannot be confirmed conclusively, which again emphasizes the problematic nature of definitively diagnosing the presence of nutrition- 
related diseases in bone. Even in cases where nutrition-related causes may be argued for, these lesions can merely be indicators of the general level of an individual or population's nutritional status and not the specific nutritional deficiencies that lead to the formation of such lesions (Kozłowski and Witas, 2012).

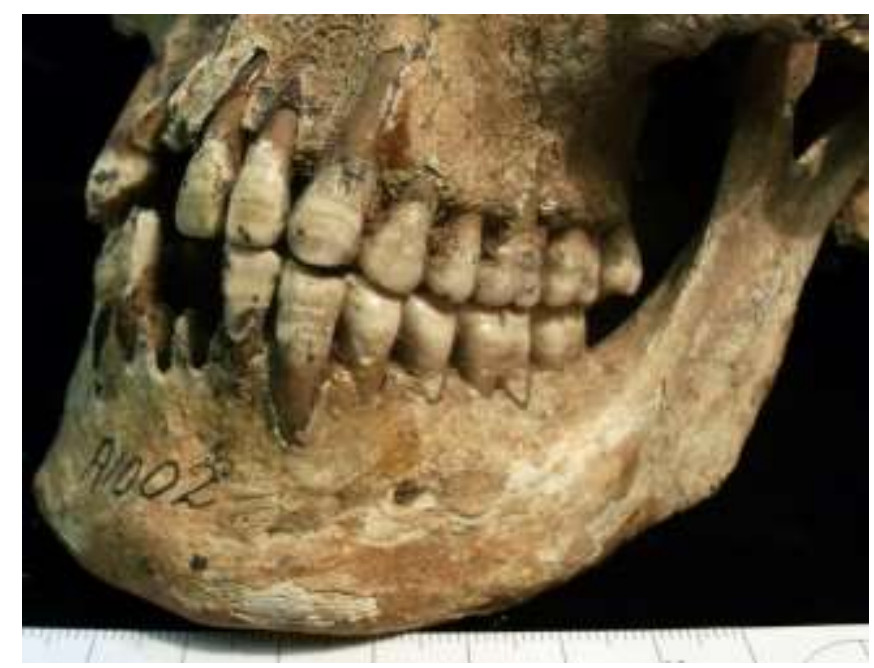

Figure 1. Linear enamel hypoplasia on the maxillary and mandibular incisors and canines in an adult male recovered from the historic Witwatersrand Deep Mine, South Africa.

Nevertheless, focus has been placed on a number of bone diseases reflecting specific vitamin- or mineral-related nutritional deficiencies. These can be collectively discussed under the term metabolic bone disease. The term 'metabolic bone disease' was coined in 1948 by Albright and Reifenstein to describe conditions affecting the processes of bone formation and remodeling in the skeleton brought on by various vitamin and mineral deficiencies (Brickley and Ives, 2008; Kozłowski and Witas, 2012). Metabolic bone diseases include an array of diseases of which the pathogenesis is quite varied and still incompletely understood (Brickley and Ives, 2008; Kozłowski and Witas, 2012). These disorders include many vitamin-related diseases like vitamin $D$ and $C$ deficiency, as well as disorders related to changing hormonal balances such as post-menopausal osteoporosis. Metabolic diseases may therefore include not only aspects of dietary stress, but also endocrine disorders resulting in hormonal imbalances (Allgrove, 2007; Brickley and Ives, 2008).

Metabolic bone diseases in the paleopathological context cannot, however, take into account the various metabolic related diseases that do not directly affect the skeleton. Recently the term, 'metabolic syndrome' which is considered a subset of metabolic disease, has received great attention (Brickley and Ives, 2008; Kozłowski and Witas, 2012). Disorders labelled under the metabolic syndrome now focus on diseases like cardiovascular disease, hypertension, high cholesterol levels, and diabetes mellitus which do not directly affect the skeleton (Agarwal, 2008; Brickley and Ives, 2008; Kozłowski and Witas, 2012). Yet some of the diseases labelled under this term, for instance obesity and diabetes, may have secondary manifestations that can become apparent as pathological alterations on the skeleton. Obesity has repeatedly been argued to increase bone mass density (BMD) thereby reducing the risk of osteoporosis (Barera et al., 2004; Zhao et al., 2007). However new insights into the effects of marrow adiposity on bone metabolism has suggested that the low-grade chronic inflammation associated with obesity may actually promote osteoclastic 
activity, whereas the high fat-content of diets usually consumed in cases of obesity inhibits calcium absorption and bioavailability necessary for normal calcium homeostasis (Cao, 2011). These inverse effects may therefore actually lead to osteoporosis. Similarly, diabetes mellitus has been associated with the development of osteopenia and osteoporosis (Bouillon, 1991; Leidig-Bruckner and Ziegler, 2001; Agarwal, 2008); however the mechanism of association, especially with type II diabetes, is still unclear (Leidig-Bruckner and Ziegler, 2001).

Even though metabolic bone disease may potentially include all nutritionally-related diseases and endocrine disease affecting the metabolic processes responsible for normal bone homeostasis, those most often focused on in the paleopathological literature are those that leave more distinctive, and arguably, more diagnostically identifiable bone pathology such as vitamin D and C deficiency, anemia, and osteoporosis.

\section{VITAMIN D DEFICIENCY}

Vitamin D (calciferol) is a pro-hormone responsible for the maintenance of calcium homeostasis and therefore plays an essential role in the proper mineralization of osteoid formed during bone growth and remodeling (Aufderheide and Rodríguez-Martin, 1998; Ortner, 2003; Brickley and Ives, 2008; Kozłowski and Witas, 2012). Without vitamin D synthesis, calcium and phosphorous, two main components of bone mineral, cannot be adequately metabolized, which in turn will severely affect the modelling and remodeling of bone (Aufderheide and Rodríguez-Martin, 1998; Ortner, 2003; Kozłowski and Witas, 2012). Vitamin D deficiency affects both children and adults and is alternatively described as rickets in children and osteomalacia in adults (Ortner, 2003; Brickley and Ives, 2008; Brickley et al., 2014). The reason for the distinctive naming is mainly attributed to differences in time of onset and the associated effects it has on bone modelling and re-modelling respectively. In the clinical literature rickets specifically refers to the disruptions in mineralization of the endochondral bone (Roberts and Manchester, 2010; Brickley et al., 2014). Therefore, it relates specifically to disruptions at the growth plate. Osteomalacia on the other hand refers to the replacement of mineralized osteoid with non-mineralized osteoid during bone remodeling, therefore affecting the cortical and trabecular bone structure and integrity (Roberts and Manchester, 2010; Brickley et al., 2014). Even though both conditions can in their clinical definitions occur in children Brickley et al. (2014) has cautioned against the interchangeable use of these two terms in paleopathology. Traditionally, bending deformities observed in adult individuals were also referred to as rickets; yet new research has shown that these deformities are the result of severe and/or reoccurring episodes of vitamin D deficiency during childhood (Brickley et al., 2010; Brickley et al., 2014). Brickley et al. (2010) therefore opted for the use of residual rickets to refer specifically to these permanent skeletal deformities.

Bony changes associated with vitamin D deficiency can be divided into those caused by the inadequate mineralization of bone osteoid and those caused by mechanical deformation of structurally weakened bone (Mays, 2008). Skeletal manifestation of rickets is first seen and most markedly so on the rapidly growing areas of the skeleton which includes the osteocartilaginous junctions of the ribs, the distal metaphysis of the femur, radius, and ulna, and the proximal humerus (Aufderheide and Rodríguez-Martin, 1998; Ortner, 2003; Brickley 
and Ives, 2008; Kozłowski and Witas, 2012). The ribs may present with round nodular swelling at the osteocartilaginous junctions, also referred to as the rachitic rosary, whereas the long bones may present with widening and cupping of the metaphysis (Ortner, 2003; Brickley and Ives, 2008; Roberts and Manchester, 2010). The vertebrae may also be affected and present with intensified kyphosis and may in some cases be associated with scoliosis (Brickley and Ives, 2008; Kozłowski and Witas, 2012). In severe cases, the accumulation of unmineralized osteoid and the weakened bone causes bending deformities in the long bones as a direct response of weight-bearing, and includes the forearm during crawling and the legs during walking (Ortner, 2003; Brickley and Ives, 2008; Kozłowski and Witas, 2012). Additionally, delayed growth may be observed in the skull (fontanel closure), the pelvis and the dentition (Brickley and Ives, 2008; Roberts and Manchester, 2010). Due to the growth disturbances, non-specific signs of stress in the form of Harris lines and enamel hypoplasia may be associated with the deficiency (Ameen et al., 2005; Kozłowski and Witas, 2012).

In cases of persistent childhood vitamin $\mathrm{D}$ and calcium deficiency, residual rickets may occur (Brickley and Ives, 2008; Brickley et al., 2010). Very few of the more subtle osteological changes, like the widening and cupping of metaphyses, associated with rickets, will survive as recognizable changes in the adult skeleton (Brinkley and Ives, 2008; Brinkley et al., 2010). In contrast, the more gross deformities of the long bones, for example the medio-lateral and anterior-posterior bowing, will be more likely to persist throughout adulthood and can therefore be used as an indicator for residual rickets in adult skeletal remains (Brickley and Ives, 2008; Brickley et al., 2010). Nevertheless, caution should be taken in diagnosing residual rickets solely on the presence of bending deformities as alternative causes such as genetic variance and trauma may also result in deformation of long bones (Stuart-Macadam et al., 1998; Kozłowski and Witas, 2012).

In adults, vitamin $D$ deficiency and the associated pathology may be very non-specific (Ortner, 2003; Brickley et al., 2005; Brickley and Ives, 2008; Kozłowski and Witas, 2012). In adults, the trabecular and compact bone undergo constant remodeling and the bone matrix formed during the disease will remain as uncalcified osteoid for as long as the deficiency persists. The first skeletal manifestation is therefore a diffuse diminished bone density that is not distinguishable from osteoporosis (Ortner, 2003; Van Schoor et al., 2007; Kozłowski and Witas, 2012). If the vitamin D deficiency persists for very long periods of time the skeleton can become sufficiently weakened to show radiolucent zones or Looser's zones, also referred to as Milkman syndrome, in areas presenting with mechanical stress (Aufderheide and Rodríguez-Martin, 1998; Ortner, 2003). The presence of pseudo fractures are especially prevalent in scapulae affecting the lateral border and inferior-lateral margins of the spinous process as well as the ribs which may present with either unhealed or healed fractures (Brickley et al., 2005; Brickley and Ives, 2008; Brickley et al., 2014). In very severe cases mechanical deformity of the skeleton due to fractures and pliability may occur (Ortner, 2003; Brickley et al., 2005; Kozłowski and Witas, 2012).

Vitamin $D$ is not a traditional vitamin and therefore requires synthesis to become actively utilized in the body (Brickley and Ives, 2008). Vitamin D synthesis requires exposure of the skin to the ultraviolet rays from sunlight or on the dietary intake of vitamin $D$ from animal fats, especially egg yolks, oily fish, and liver (Pettifor, 2004; Brickley and Ives, 2008, Kozłowski and Witas, 2012; Brickley et al., 2014). Nevertheless, even in the absence of 
vitamin $\mathrm{D}$ deficiency, a calcium and/or phosphorous deficiency should also be considered as possible causes of altered bone modeling or remodeling as both these elements are necessary for healthy osteoid formation. This was also confirmed by a study conducted by Pettifor (2004) on South African children, who were readily exposed to ultraviolet rays, but still presented with rickets. In this case, the lack of exposure to sunlight was not found to be the debilitating factor, but rather the severe lack of calcium in these children's diet. A major characteristic of diets in both rural South Africa and Nigeria is a high concentration of especially unrefined cereals (Pettifor, 2004). These cereals have a high content of phytate which in turn impairs calcium absorption (Pettifor, 2004; Brickley et al., 2014). It was therefore suggested that the major cause for rickets among children was a dietary calcium deficiency, rather than a vitamin D deficiency (Pettifor, 2004). Severe cases of calcium deficiency may additionally result in secondary hyperparathyroidism, which in turn will have an effect on the bone structure and health (Brickley et al., 2014). Similarly, Özgür et al. (1996) suggested that high levels of strontium may inhibit the parathyroid glands, leading to a reduction in the production of active vitamin $D$ metabolites by the kidneys. They concluded that in populations where nutrition is mainly based on grain cereals, the presence of strontium in the soil will increase the prevalence of rickets significantly (Özgür et al., 1996).

Specific dietary preferences may also lead to a deficiency in vitamin D and calcium. Children and adults consuming strict vegan and vegetarian diets have been shown to be more prone to developing vitamin D deficiency (Curtis et al., 1983; Messina and Mangels, 2001; Murphy and Allen, 2003; Brickley et al., 2014). Such strict diets are devoid of any animal products and without supplementation drastically limit the amount of vitamin $D$ and calcium being consumed (Curtis et al., 1983; Messina and Mangels, 2001; Murphy and Allen, 2003; Pettifor, 2004). Excessive ethanol consumption is also associated with secondary or conditioned nutritional deficiencies. Individuals suffering from chronic alcoholism are known to have diets that are nutritionally severely deficient and often present with impaired liver and kidney function which further inhibits vitamin D and calcium metabolism (Brickley and Ives, 2008; Arteh et al., 2010). The manifestation of osteomalacia and osteoporosis can therefore potentially be observed in alcohol dependent individuals (Spencer et al., 1986; Chakkalakal, 2005; Park et al., 2014).

\section{SCURVY}

Scurvy, also known as Moller-Barlow's disease, is a metabolic disease caused by a vitamin C (ascorbic acid) deficiency (Aufderheide and Rodríguez-Martin, 1998; Ortner, 2003; Brickley and Ives, 2008; Waldron, 2009; Kozłowski and Witas, 2012). Humans are unable to synthesize vitamin $C$ and must acquire it solely through their diet (Mays, 2008; Brickley and Ives, 2008; Waldron, 2009). Vitamin C is available from a large range of foods, especially fresh fruits and vegetables, but also to some extent in milk, fish, and meat (Brickley and Ives, 2008; Mays, 2008; Kozłowski and Witas, 2012). Vitamin C can, however, easily be destroyed by high temperatures and by exposure to air, resulting in the deficiency being more prevalent in populations consuming mainly cooked and processed foods. Adult scurvy has been recognized worldwide as a serious disease that has caused high mortality amongst people throughout history, usually taking place during times when people were deprived of 
fresh fruit and vegetables due to war, famine, or in some cases prolonged trips at sea (Maat, 2004; Mays, 2008).

In paleopathology, the effects of scurvy on the human skeleton can be very subtle, especially in adults, as the disease is mainly linked to soft tissue changes (Kozłowski and Witas, 2012; Armelagos et al., 2014). Vitamin C is responsible for collagen formation and as a result can cause general weakness of connective tissue as well as weakness in the walls of blood vessels should it be found lacking (Aufderheide and Rodríguez-Martin, 1998; Ortner, 2003; Maat, 2004; Mays, 2008; Kozłowski and Witas, 2012). These weaknesses cause hemorrhaging and if it occurs adjacent to bone it may provoke an osteological response (Aufderheide and Rodríguez-Martin, 1998; Ortner, 2003; Mays, 2008; Brickley and Ives, 2008). Skeletal changes observed in scurvy can either be due to the direct effect of the vitamin C deficiency or due to secondary changes caused by trauma in the vulnerable scorbutic bone and associated blood vessels (Brickley and Ives, 2008; Kozłowski and Witas, 2012). The primary lesion consists of the combined effect of severely diminished osteoblastic activity and continued osteoclastic and chondroclastic activity. Complete exclusion of vitamin $C$ from the human diet is quite rare. Humans also require very small amounts of vitamin $\mathrm{C}$ supplementation following a deficiency to produce a considerable reaction and new bone formation at the periosteum (Brickley and Ives, 2008; Kozłowski and Witas, 2012).

Subperiosteal hemorrhaging caused by vitamin C deficiency may be very marked in children due to the fact that the periosteum is not yet firmly attached. Inflammation associated with bleeding will cause symmetrical inflammation and bone surface porosity in many areas throughout the skeleton followed by cessation of new bone formation with weakening of bone structures, in turn resulting in metaphyseal fractures (Aufderheide and RodríguezMartin, 1998; Ortner, 2003; Brickley and Ives, 2008). The skull is often involved and may present with porous lesions to the greater wings of the sphenoid and zygomatic bones, as well as the posterior surface of the maxilla, coronoid process of the mandible with subperiosteal hemorrhaging on the frontal bone and particularly on the portion that forms the orbital roof (Ortner, 2003; Kozłowski and Witas, 2012). Due to the inflammation of the gums, periodontal disease and antemortem tooth loss are also often associated with scurvy (Ortner, 2003; Brickley and Ives, 2008). Additionally, the potential for enamel hypoplastic defects are high, as the deficiency will invariably lead to growth stunts and/or a diminished immune system resulting in frequent infection and/or illness. However, dental pathology cannot on its own serve as a diagnostic criterion for the presence of scurvy, as many other disease processes may cause similar responses. Even a diagnosis based on bone porosity is quite problematic, as other metabolic bone diseases such as vitamin D deficiency and anemia may also cause the appearance of porotic lesions (Brickley and Ives, 2008; Kozłowski and Witas, 2012; Armelagos et al., 2014). Even though Ortner et al. (1999) argued for a distinct skeletal distribution of porotic lesions associated with scurvy, this may become difficult in situations where individuals suffered from more than one vitamin deficiency. This is especially the case with anemia as vitamin C plays an active role in blood formation and the metabolism of iron and folate. Therefore individuals suffering from severe scurvy often also present with anemia which may in turn present with very similar skeletal type pathologies (Brickley and Ives, 2008; Armelagos et al., 2014). 
Osteological responses to scurvy in adults tend to be minor and very non-specific, which makes definitive diagnosis problematic. Skeletal lesions that may potentially be associated with adult scurvy include new bone formation in the orbits in the form of cribra orbitalia and on the ends of the long bones as subperiosteal bone growth, as well as inflammation of the alveolar bone often resulting in subsequent antemortem tooth loss (Aufderheide and Rodríguez-Martin, 1998; Hirschmann and Gregory, 1999; Ortner, 2003; Brickley and Ives, 2008; Kozłowski and Witas, 2012). Even though the skeletal manifestation of adult scurvy is very non-specific there seems to be cases where a specific diagnosis was possible. Two cases where adult scurvy has been positively diagnosed in osteoarchaeological material include a study by Maat (2004) and Van der Merwe et al. (2010a,b). These two studies clearly diagnosed the presence of adult scurvy in osteoarchaeological human remains by linking the osteological manifestations observed with the clinical signs and symptoms associated with the deficiency. The first study, done on the remains of 50 Dutch whalers who had been buried during the 17th and 18th centuries on an island of Spitsbergen Archipelago, indicated that dark stains observed on the long bones where synonymous with hemorrhaging clinically associated with scurvy (Maat, 2004). The second study, done on a 19th century mining population from Kimberley, South Africa, indicated the presence of subperiosteal lesions on the long bones (Van der Merwe et al., 2010a, 2010b). These lesions were histologically diagnosed as being ossified hematomas, again supporting the clinical literature in the disease manifestation.

\section{ANEMIA}

Iron is essential for many bodily functions and is especially an essential element in hemoglobin, thus enabling the sufficient transport of oxygen throughout the body tissues (Larsen, 1997; Steckel, 2005; Kozłowski and Witas, 2012). Iron absorption from the diet is dependent upon its source within the foods consumed, either being heme or nonheme (Larsen, 1997). Generally, heme sources of iron are efficiently absorbed, with meat being the best source (Larsen, 1997). Iron in meat does not require processing in the stomach and the amino acids from the digestion of meat help to enhance iron absorption (Larsen, 1997). Nonheme sources include most of the plant sources and the iron contained in it is generally poorly absorbed with various substances found in plants inhibiting iron absorption. These include phytates found in many nuts, cereals, and legumes (Larsen, 1997). A number of foods are known to enhance the absorption of iron, the most common being vitamin $C$ enriched foods (Larsen, 1997). For this reason, vitamin C and iron deficiency may often occur simultaneously.

Skeletal manifestation of the disease is not always prevalent, but where it is, these changes are part of a generalized syndrome which may include porotic hyperostosis (lesions on the outer table of the cranial vaults), and cribra orbitalia (Fig. 2; lesions found in the roof areas of the orbits) (Aufderheide and Rodríguez-Martin, 1998; Larsen 1997; Ortner, 2003; Kozłowski and Witas, 2012). These lesions are usually caused by marrow hyperplasia and present as areas of pitting and/or porosity on the external surfaces of bone as a result of the expansion of the diploë (Ortner, 2003; Walker et al., 2009). Severe cases of cribra orbitalia present with deep pores in the orbital roofs whereas porotic hyperostosis may have a "hairon-end" appearance (Fig. 3) which is especially observable in radiographs (Ortner, 2003). 


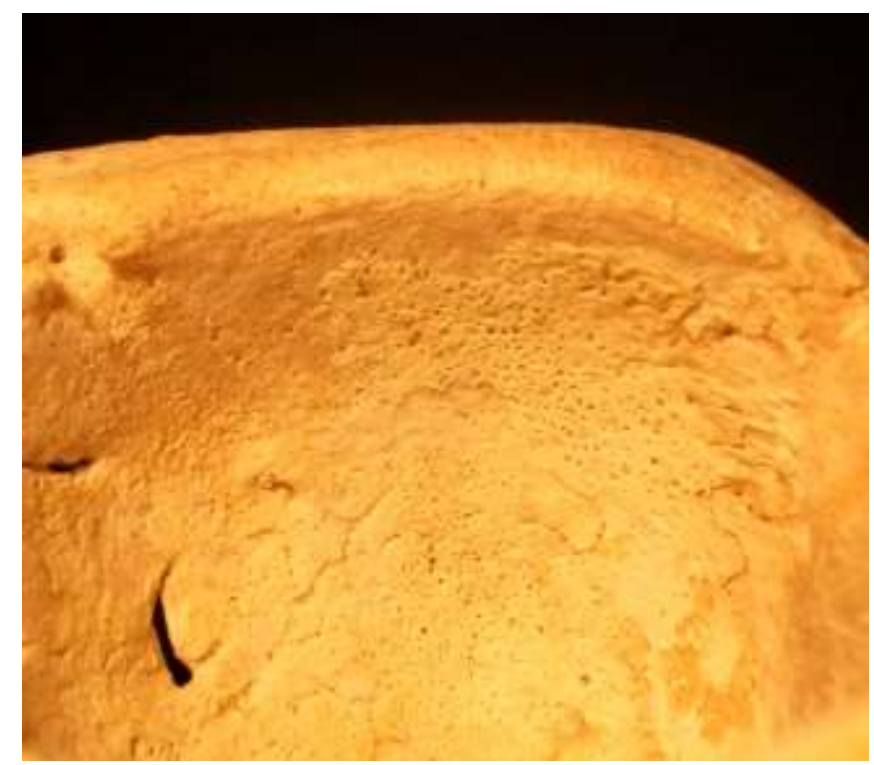

Figure 2. Cribra orbitalia in an adult male from the Raymond A Dart Collection, University of the Witwatersrand.

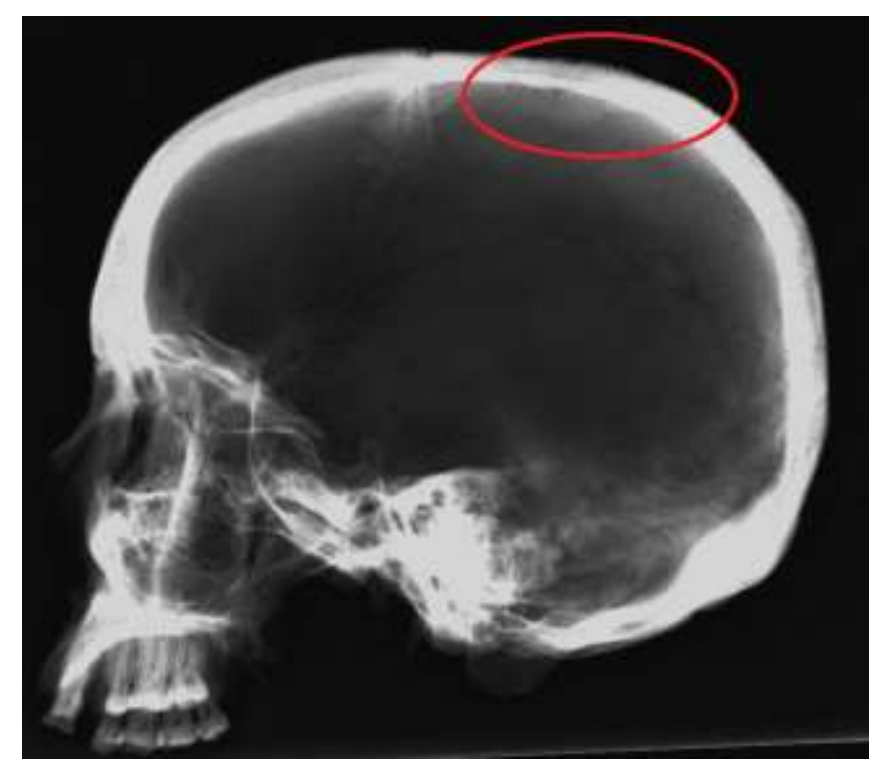

Figure 3. "Hair-on-end" appearance associated with porotic hyperostosis in an adult male from the historic Witwatersrand Deep Mine, South Africa.

Even though cribra orbitalia and porotic hyperostosis have repeatedly been ascribed to iron deficiency anemia (Stuart-Macadam, 1985, 1992; Walker et al., 2009; Kozłowski and Witas, 2012 ) the specific diagnosis in the past remains complex. A wide range of potential causative factors have been discussed and include genetic mutations which affect red blood cell production, shortages of iron in the diet, intestinal parasitic infections compromising iron absorption in the intestinal tract, infections which trigger the body to reduce serum iron levels, intensive hemorrhage, and/or excessive blood loss (Stuart-Macadam, 1989; Steckel, 2005; Brickley and Ives, 2008; Kozłowski and Witas, 2012).

The iron deficiency anemia theory has however recently been disclaimed by Walker et al. (2009) who argued that iron deficiency decreases the production of mature red blood cells 
and therefore cannot cause bone marrow hyperplasia. Oxenham and Cavill (2010), on the other hand, suggested that this is not necessarily the case and that even though iron deficiency decreases the production rate for functional erythrocytes, the actual erythropoietic activity is increased. This suggests that bone marrow hyperplasia and the hypertrophic lesions associated with it can indeed occur as a result of iron deficiency anemia. The appearance of hypertrophic lesions may therefore be caused by hemolytic anemia (thalassemia and sickle cell anemia), megaloblastic anemia (chronic dietary deficiency, malabsorption, and deficiencies of the vitamins B12 and B9), and iron deficiency anemia (Walker et al., 2009; Oxenham and Cavill, 2010). It should, however, be emphasized that anemia is but one of many possible causes of cribra orbitalia. A study by Wapler et al. (2004) showed that in at least $56.5 \%$ of the cases where cribra orbitalia could be observed there were no histological features indicating changes as a result of anemia. They provided several alternative reasons for the wide-spread occurrence of cribra orbitalia. These include inflammation (osteitis, periostitis, and hypervascularization), which can be caused by the spreading of other infections (this may include sinusitis, tooth abscesses, and other oral infections, nasopharyngeal infections, and suppurating skin inflammations); other undetermined causes such as additional underlying metabolic diseases (scurvy, rickets, and osteoporosis), localized pressure as a result of an enlarged organ (for example, the lacrimal gland); and postmortem erosion as a factor of taphonomic alterations (Wapler et al., 2004).

\section{DISCUSSION}

Bone pathology can and have been used to infer aspects of diet and nutrition-related deficiencies in past populations; however precise diagnoses of specific vitamin-related deficiencies are still quite problematic and definitive diagnoses are rarely possible. This partly stems from the fact that many nutritional or metabolic diseases do not necessarily result in an osteological response. Most diseases, especially the more fatal ones, will only affect the soft tissues at most, leaving no indication of its presence on the skeletal remains (Ortner, 2003; Waldron, 2009). Except in cases where organs and soft tissues are preserved (for example, in mummified remains), paleopathological studies are largely limited to those conditions affecting the skeletal system. Some nutritional diseases may present as diagnostic pathological lesions on the skeleton whereas others may only present as nonspecific markers of stress (Roberts and Manchester, 2010; Ortner, 2003; Waldron, 2009).

Following Wood et al. (1992) it should also be kept in mind that not all individuals would necessarily present with bony lesions even in the presence of a deficiency. This particularly pertains to the effects of selective mortality and hidden heterogeneity, on paleopathologists either having access to individuals presenting with bony lesions or affected individuals actually presenting with disease-related osteological markers. Since paleopathological studies are based on the prevalence of skeletal lesions it should ideally be able to control for individual differences, yet due to the nature of the discipline this becomes problematic as only individuals with skeletal pathology end up in paleopathological studies. Due to the variability of individual responses to metabolic insults, it becomes problematic to interpret skeletal lesions solely as an indicator of ill health. The presence of skeletal lesions indicates that the person lived long enough for the nutritional deficiency to affect the skeleton, yet that the individual did not immediately succumb to the disease. This would suggest a state of relative good health as supposed to an individual who would succumb to the disease 
before the appearance of skeletal lesions. Survival time therefore plays an important role in whether the disease could become chronic enough for an osteological response to occur. Skeletal manifestations thus depend on both the severity of the nutritional deficiency and the survival time. Survival time may in itself depend on a multitude of extrinsic and intrinsic factors, either on an individual level (variability of disease prevalence and susceptibility to disease and death in each human being) or in terms of the regional, temporal, and sociocultural differences of different populations throughout time (Wood et al., 1992). For instance, some of the metabolic bone diseases like scurvy and anemia may present with a higher mortality rate as well as a quick recovery rate, which minimizes the chances of osteological manifestations and the eventual recognition of such diseases in past populations.

Even when osteological manifestations of metabolic diseases can be observed, comorbidity and analogous osteological responses to vitamin deficiencies may hamper the definite diagnosis of the disease. Even when working from a modern clinical base, paleopathologists are still limited in their ability to diagnose specific vitamin or mineral deficiencies as they rarely have access to individual life histories. Comparing the incidence of skeletal pathology in the archaeological remains studied with that of well-documented modern-day medical collections may aid in the interpretation of skeletal pathology and its diagnosis (Wood et al., 1992). Yet, even these collections contain selection bias and do not always provide complete medical histories, which are essential for understanding factors of comorbidity. Fortunately, the advancement of new 3D imaging techniques and biomolecular and genetic studies are now at a point where it can be readily used in line with macroscopic assessment of paleopathological specimens. Paleopathology has much to offer in the sense that it is inherently a multidisciplinary field and can draw from archaeological as well as modern-day clinical sources of information to better our understanding of past health and diet.

\section{REFERENCES}

Adams P, Berridge FR. 1969. Effects of Kwashiorkor on cortical and trabecular bone. Arch Dis Childh 44:705-709.

Agarwal SC. 2008. Light and broken bones: examining and interpreting bone loss and osteoporosis in past populations. In: Katzenberg MA, Saunders SR, editors. Biological Anthropology of the Human Skeleton. 2nd Ed. Hoboken, NJ: John Wiley and Sons. p 387410.

Alfonso-Durruty MP. 2011. Experimental assessment of nutrition and bone growth's velocity effects on Harris lines formation. Am J Phys Anthropol 145:169-180.

Allgrove J. 2007. Metabolic bone disease. Paediatr Child Health 17:253-259.

Ameen S, Staub L, Ulrich S, Vock P, Balmer F, Anderson SE. 2005. Harris Lines of the tibia across centuries: A comparison of two populations, Medieval and contemporary in Central Europe. Skelet Radiol 34:279-284. 
Angel JA. 1978. Pelvic inlet form: A neglected index of nutritional status. Am J Phys Anthropol (Abstract) 48:378.

Angel JA. 1982. A new measure of growth efficiency: Skull base height. Am J Phys Anthropol 58:297-305.

Armelagos GJ, Siraka K, Werkemaa T, Turnerb BL. 2014. Analysis of nutritional disease in prehistory: The search for scurvy in antiquity and today. Int J Paleopathol 5:9-17.

Arteh J, Narra S, Nair S. 2010. Prevalence of vitamin D deficiency in chronic liver disease. Dig Dis Sci 55:2624-2628.

Aufderheide AC, Rodríguez-Martin C. 1998. The Cambridge Encyclopedia of Human Paleopathology. Cambridge: Cambridge University Press.

Barrera G, Bunout D, Gattás V, Pía de la Maza M, Leiva L, Hirsch S. 2004. A high Body Mass Index protects against femoral neck osteoporosis in healthy elderly subjects. Nutrition 20:769-771.

Bouillon R. 1991. Diabetic bone disease. Calcif Tissue Int 49:155-160.

Brickley MB, Ives R. 2008. The Bioarchaeology of Metabolic Bone Disease. London: Elsevier Academic Press.

Brickley MB, Mays S, Ives R. 2005. Skeletal manifestations of Vitamin D deficiency osteomalacia in documented historical collections. Int J Osteoarchaeol 15:389-403.

Brickley MB, Mays S, Ives R. 2010. Evaluation and interpretation of residual rickets deformities in adults. Int J Osteoarchaeol 20:54-66. Brickley MB, Moffat T, Watamaniuk L. 2014. Biocultural perspectives of vitamin D deficiency in the past. J Anthropol Archaeol 36:48-59.

Cao JJ. 2011. Effects of obesity on bone metabolism. J Orthop Surg Res 6:30.

Chakkalakal DA. 2005. Alcohol-induced bone loss and deficient bone repair. Alcohol Clin Exp Res 29:2077-2090.

Curtis JA, Kooh SW, Fraser D, Greenberg ML. 1983. Nutritional rickets in vegetarian children. Can Med Assoc J 128:150-152.

Goodman AH, Rose JC. 1991. Dental enamel hypoplasias as indicators of nutritional status. In: Kelley MA, Larsen CS, editors. Advances in Dental Anthropology. New York: Alan R. Liss. p 129-160.

Harris HA. 1933. Bone Growth in Health and Disease. London: Oxford University Press.

Hirschmann JV, Gregory JR. 1999. Adult scurvy. J Am Acad Dermatol 41:895-906. 
Huss-Ashmore R, Goodman AH, Armelagos GJ. 1982. Nutritional inference from paleopathology. Adv Archaeol Meth Theor 5:395-474.

Kozłowski T, Witas HW. 2012. Metabolic and endocrine diseases. In: Grauer AL. editor. A Companion to Paleopathology. Chichester, UK: Wiley-Blackwell. p 401-419.

Larsen CS. 1997. Bioarchaeology. Interpreting Behavior from the Human Skeleton. Cambridge: Cambridge University Press.

Larsen CS. 2002. Bioarchaeology: The lives and lifestyles of past people. J Archaeol Res 10:119-166.

Leidig-Bruckner G, Ziegler R. 2001. Diabetes mellitus a risk for osteoporosis? Exp Clin Endocr Diab 109:S493-S514.

Lukacs JR. 2012. Oral health in past populations: Context, concepts, and controversies. In: Grauer AL, editor. A Companion to Paleopathology. Chichester, UK: Wiley-Blackwell. p 553581.

Maat GJR. 2004. Scurvy in adults and youngsters: the Dutch experience. A review of the history and pathology of a disregarded disease. Int J Osteoarchaeol 14:77-81.

Mays S. 2008. Metabolic bone disease. In: Pinhasi R, Mays S, editors. Advances in Paleopathology of Teeth and Jaws. West Sussex, England: John Wiley \& Sons Ltd. p 215-251.

Messina V, Mangels AR. 2001. Considerations in planning vegan diets: Children. J Am Diet Assoc 101:661-669.

Murphy SP, Allen LH. 2003. Nutritional importance of animal source foods. J Nutr 133:3932S-3935S.

Ogden A. 2008. Advances in paleopathology of teeth and jaws. In: Pinhasi R, Mays S, editors. Advances in Paleopathology of Teeth and Jaws. West Sussex, England: John Wiley \& Sons Ltd. p 283-308.

Ortner DJ. 2003. Identification of Pathological Conditions in Human Skeletal Remains. Amsterdam: Academic Press.

Ortner DJ, Kimmerle EH, Diez M. 1999. Probable evidence of scurvy in subadults from archaeological sites in Peru. Am J Phys Anthropol 108:321-331.

Oxenham MF, Cavill I. 2010. Porotic hyperostosis and cribra orbitalia: the erythropoietic response to iron-deficiency anemia. Anthropol Sci 118:199-200.

Özgür S, Sümer H, Koçoğlu G. 1996. Rickets and soil strontium. Arch Dis Child 75:524-526.

Papageorgopoulou C, Suter SK, Rühli FJ, Siegmund F. 2011. Harris lines revisited: prevalence, comorbidities, and possible etiologies. Am J Hum Biol 23:381-391. 
Park B, Lee Y, Lee H. 2014. Chronic liver inflammation: Clinical implications beyond alcoholic liver disease. World J Gastroenterol 20:2168-2175.

Pettifor JM. 2004. Nutritional rickets: Deficiency of vitamin D, calcium, or both? Am J Clin Nutr 80:1725S-1729S.

Purvis RJ, Mackay GS, Cockburn F, McK Barrie WJ, Wilkinson EM, Belton NR, Forfar JO. 1973. Enamel hypoplasia of the teeth associated with neonatal tetany manifestation of maternal vitamin-D deficiency. Lancet 811-814.

Roberts CA, Manchester K. 2010. The Archaeology of Disease. 3rd Ed. Gloucestershire: The History Press.

Spencer H, Rubio N, Rubio E, Indreika M, Seitam A. 1986. Chronic alcoholism. Frequently overlooked cause of osteoporosis in men. Am J Med 80:393-397.

Steckel RH. 2005. Young adult mortality following severe physiological stress in childhood: Skeletal evidence. Econ Hum Biol 3:314-328.

Stuart-Macadam PL. 1985. Porotic hyperostosis: Representative of a childhood condition. Am J Phys Anthropol 66:391-398.

Stuart-Macadam PL. 1989. Nutritional deficiency diseases: A survey of scurvy, rickets, and iron-deficiency anemia. In: Iscan, MY, Kennedy, AR, editors. Reconstruction of Life From the Skeleton. New York: Alan R. Liss. p 201-222.

Stuart-Macadam PL. 1992. Porotic hyperostosis: A new perspective. Am J Phys Anthropol 87:39-47.

Stuart-Macadam P, Glencross B, Kricun M. 1998. Traumatic bowing deformities in tubular bones. Int J Osteoarchaeol 8:252-262.

Van der Merwe AE, Steyn M, Maat GRJ. 2010a. Ossified hematomas and infectious bone changes on the anterior tibia: Histomorphological features as an aid for accurate diagnosis. Int J Osteoarchaeol 20:227-239.

Van der Merwe AE, Steyn M, Maat GRJ. 2010b. Adult scurvy in skeletal remains of late 19th century mineworkers in Kimberley, South Africa. Int J Osteoarchaeol 20:307-316.

Van Schoor NM, Visser M, Pluijm SMF, Kuchuk N, Smit JH, Lips P. 2007. Vitamin D deficiency as a risk factor for osteoporotic fractures. Bone 42:260-266.

Waldron T. 2009. Palaeopathology. Cambridge: Cambridge University Press.

Walker PL, Bathurst RR, Richman R, Gjerdrum T, Andrushko VA. 2009. The causes of porotic hyperostosis and cribra orbitalia: A reappraisal of the iron-deficiency-anemia hypothesis. Am J Phys Anthropol 139:109-125. 
Wapler U, Crubézy E, Schultz M. 2004. Is cribra orbitalia synonymous with anemia? Analysis and interpretation of cranial pathology in Sudan. Am J Phys Anthropol 123:333-339.

Weston DA. 2012. Nonspecific infection in paleopathology: Interpreting periosteal reactions. In: Grauer AL, editor. A Companion to Paleopathology. Chichester, UK: Wiley-Blackwell. p 492-512.

Wood JW, Milner GR, Harpending HC, Weiss KM, Cohen MN, Eisenberg LE, Hutchinson DL, Jankauskas R, Cesnys G, Česnys G, Katzenberg MA, Lukacs JR, McGrath JW, Roth EA, Ubelaker DH, Wilkinson RG. 1992. The osteological paradox: problems of inferring prehistoric health from skeletal samples. Curr Anthropol 33:343-370.

Zhao L, Jiang H, Papasian CJ, Maulik D, Drees B, Hamilton J, Deng H. 2007. Correlation of obesity and osteoporosis: Effect of fat mass on the determination of osteoporosis. J Bone Miner Res 23:17-29. 